\title{
The Effectiveness of Implicit and Explicit Cognitive Processing in Incidental Vocabulary Acquisition
}

\author{
Kübra Örsdemir a* (D) \\ a Osmaniye Korkut Ata University, Osmaniye, Turkey
}

Received 18 July 2017 | Received in revised form 11 September 2017 | Accepted 27 September 2017

\begin{abstract}
This article tends to investigate the lexical processing strategies adopted by 12 elementary level participants while doing reading-for-comprehension activities together with the effectiveness of these strategies on the retention of new vocabulary items in incidental vocabulary acquisition. The participants who took part in the research studied at an English Preparatory School in Turkey. Through these procedures, incidental vocabulary acquisition through reading for-comprehension tasks were aimed to be investigated since the Input Hypothesis suggests that incidental learning of vocabulary can be attained through reading. During the reading process, the adopted strategies were investigated through the introspective data gathered by the researcher. Later, the participants attended to a reading comprehension process and finally the participants participated in a post-test which is known to be the 'Vocabulary Knowledge Scale'. Through this scale the rate of retention of the participants for each vocabulary item was identified in accordance with related scoring procedures. The adopted strategies were then categorized in relation to the cognitive processing styles. Through this treatment the effectiveness of retention through implicit and explicit processing in incidental vocabulary acquisition was examined. The findings suggest that implicit processing strategies result to be more effective in terms of incidental vocabulary acquisition.
\end{abstract}

(C) 2017 EJAL \& the Authors. Published by Eurasian Journal of Applied Linguistics (EJAL). This is an open-access article distributed under the terms and conditions of the Creative Commons Attribution license (CC BY-NC-ND) (http://creativecommons.org/licenses/by-nc-nd/4.0/).

Keywords: Incidental vocabulary acquisition; input hypothesis; lexical processing strategies; retention

\section{Introduction}

Vocabulary acquisition has been a challenge for language learners since improving vocabulary knowledge is vital in language learning. As a result, learners and language teachers are well aware of the importance of the development of the lexicon. Various methods, techniques and styles have been applied in language classrooms in order to achieve this goal. One of the major methods of vocabulary expansion is thought to be the assumption that words are learned incidentally or indirectly in reading and that this learning is of vital importance in vocabulary acquisition

\footnotetext{
* Corresponding author name.

E-mail address: kubraorsdemir@hotmail.com

http://dx.doi.org/.......
} 
(Krashen, 1989; Paribakht \& Wesche, 1999). Incidental or indirect vocabulary learning is the process in which the learning of the vocabulary occurs without the specific intent to focus on vocabulary itself (Joe, 1998). In other words, it is an effective way of learning word meanings from context and it can also be a by-product of other cognitive exercises involving comprehension (Gass, 1999). In this study, incidental vocabulary acquisition has been aimed to be researched upon in a more detailed way through reading-for comprehension activities. As a result, it is aimed to notify how the participants grasp vocabulary through explicit and implicit processing by reading.

\subsection{Implicit/Expicit Processing - Incidental/Intentional Learning}

Krashen (1989) suggests in his 'Input Hypothesis' that we acquire language by understanding messages through comprehensible input and also through a richly specified internal language acquisition device (p. 441). He makes a distinction between two types of processing, in one of which the acquisition is done subconsciously through the language acquisition device, and in the other the knowledge is consciously learned and it is quite limited which entails a higher frequency of monitoring. These two types of processing can be linked to implicit and explicit processing. He also argues that, the most effective way to acquire spelling and vocabulary is by attaining comprehensible input through reading.

Ellis (1994) states that explicit learning of vocabulary is encompasses selective attention and the use of strategies to comprehend the meanings of a lexical unit. Similarly, Hulstijn (2005, p. 131) states, "explicit learning is input processing to find out whether the input information contains regularities and if so, to work out the concepts and rules with which these regularities can be captured" (as cited in Brown, 2000), whereas implicit learning is learning without conscious awareness. Brown (2000), on the other hand, states that attention, which is a psychological state of focusing on certain stimuli, can occur under both conditions. According to Ellis (2005), implicit and explicit knowledge can be distinguished in seven ways. These are listed below

- Awareness: There are two types of awareness; the unconscious awareness associated with epilinguistic behavior (as when we can recognize instantly that a sentence is ungrammatical) and the conscious awareness evident in metalinguistic behavior (as when we demonstrate understanding of why a sentence is ungrammatical) (p.433).

- Type of Knowledge: Declarative knowledge of grammatical features is identified to be encyclopedic since it consists of 'facts' about the grammar of a language, on the other hand, Procedural knowledge is represented in such a way that it can be easily accessed. This dimension of the implicit/explicit distinction, then, assumes that how the two types of knowledge are represented relates to how they are processed. (p.433)

- Systemacity and Certainty of L2 Knowledge: While Implicit knowledge is produced systematically in the learners' interlanguage, explicit knowledge is generally 
imprecise and inaccurate. As a result, implicit knowledge can be identified to be more structured than explicit knowledge and can be held with greater certainty

- Accessibility of Knowledge: It is suggested that deeply embedded knowledge which can be referred to as implicit knowledge allows for automatic processing, the more weakly held knowledge, which can be referred to as explicit knowledge requires more controlled processing.

- Use of L2 knowledge: The use of the two types of knowledge differs in terms of identifying under which circumstances the learners are asked to perform tasks. For instance, if the learners have less pressure with lower affective filters they are their speech becomes more accurate since the learners have the chance to access their explicit knowledge. Whereas, learners who are asked to perform tasks rapidly under pressure, are less accurate since they rely only upon their implicit knowledge.

- Self-Report: Explicit knowledge is defined to be verbalized. For instance, a student can explain why he/she used a specific grammatical form in a specific situation

- Learnability: It is generally assumed that while explicit knowledge can be learnt at any age, implicit knowledge cannot at all ages.

According to Ellis (2005), while the first three ways of the differentiation of explicit and implicit knowledge is defined to be 'Representation Dimensions', the remaining four ways can be classified to be 'Processing dimensions'. It can be assumed through these definitions that, while examining implicit and explicit knowledge different strategies and different tasks should be applied since they are different in terms of representation and processing.

Incidental and intentional learning, on the other hand are closely linked to implicit and explicit learning. While intentional learning is deliberately focusing on thousands of words (their meaning, sound and spelling) and various grammar rules, incidental learning involves the "picking up" of words and structures. Krashen (1989) states that in incidental learning, the language acquisition device is active during which your conscious focus is on the message, not on the form. Also, by engaging in a variety of communicative activities, especially through reading and listening activities since the learner's attention is focused on the meaning rather than on the form of language, these kinds of activities facilitate incidental learning (Hulstijn, 2008). Paribahkt and Wesche (1997) also state that even though aural language experience is important written language generally contains a higher proportion of difficult or low frequency words, as a result they further state that reading is a vehicle for further developing both L1 and L2 vocabulary knowledge. According to Krashen (1989), children who perform better on vocabulary tests are noticed to be the ones who prefer to read more especially in out-of-class environments. This statement can also notify how reading can promote vocabulary learning incidentally, implicitly or even intentionally, a method to measure can be the Incidental Read and Test studies in which the participants focus on the comprehension of the whole passage rather than on individual words, hence through comprehensible input it can be possible to infer meanings from a whole text (Krashen, 1989). Similarly, Paribahkt and Wesche (1999) 
state that "both first and second language development supports the conclusion that most vocabulary learning occurs naturally when learners attempt to understand new words they hear or read in context" (p. 196). As a result, it will not be wrong to say that vocabulary growth and reading comprehension can be linked very strongly since each of the variables affects one another. The comprehension and the intake of new lexical knowledge while reading involves inferencing, which is a cognitive process that involves making informed guesses as to the meaning of a word in light of all available linguistic cues in combinations with the learner's general knowledge of the world (Paribahkt and Wesche, 1999).

According to Hulstijn (2008), incidental and intentional learnings are mainly dominant in the area of vocabulary and spelling, and only exceptionally in the area of grammar (morphology and syntax); the reason why intentional learning is valid in vocabulary learning but hardly in grammar learning, whereas incidental is valid in both areas is due to the fact that incidental learning can apply to abstract and to factual declarative knowledge, on the other hand, intentional learning can be applicable to factual knowledge.

As for the difference between implicit/incidental and explicit/intentional, Paradis (1994) states that implicit learning entails more than what is meant by incidental learning since incidental and implicit are distinguished through implicit competence, knowledge which is acquired incidentally (not by focused attention), stored implicitly (not available to conscious awareness), and used automatically (without conscious control) (cited in Hulstijn, 2008). Similarly, Ender (2014) states that the unintentional retention through incidental learning should not be equated with implicit learning, since implicit learning is the counterpart of explicit learning and it is defined as input processing with the conscious intention to find out whether the input conformation contains regularities, and if so, to work out the concepts and rules with which these regularities can be captured. The difference of intentional and explicit learning is, while explicit learning involves awareness at the point of learning, such as trying to understand the function of a language form, intentional learning, on the other hand, involves a deliberate attempt to commit new information to memory, such as applying rehearsal or memorizations (Hulstijn, 2008).

+/- Intentional learning

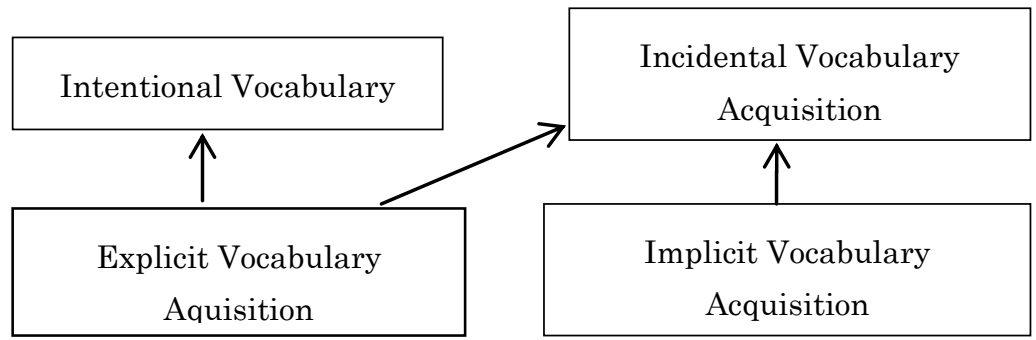

Figure 1. The relationship between incidental/intentional and implicit/explicit processing (Ender, 2014)

As can be seen in Figure 1, while intentional and incidental vocabulary acquisition is about learning the vocabulary in a specific task, explicit and implicit vocabulary 
acquisition deal with the processing which takes place while accomplishing a task. Also it can be seen that while intentional learning can only result from processing, since there is an intention to learn a certain from, incidental learning on the other hand, can result from both explicit processing, since processing with the conscious intention to discover the form and meaning relations can still occur without the intention to retain the findings in the long term (Ender, 2014, p.538); Krashen (1989) also states that acquisition can also occur without learning and implicit processing.

\subsection{Lexical Processing Strategies}

Laufer (1990, p. 2) states that a word comprises complex features (phonological, orthographic, morphological, syntactic, semantic) and also a word is related to other words in a language, hence, the knowledge of a word is related to familiarities with these features and with the lexical relations of the word. Similar to this statement, in order to acquire vocabulary Fraser (1999) suggests lexical processing strategies (LPSs) which refers to three strategic options, these are; ignore and continue reading, consult a dictionary or another individual, or infer word meaning on the basis of linguistic (these can be sub-divided as interlingual and intralingual) and contextual cues. Ender (2014) states that, apart from ignoring, the remaining lexical processing strategies take an explicit aim at determining the word's meaning, and also she states that these strategies can easily be combined. These can be linked with top-down and bottom-up strategies; as Qian (2004) suggests while consulting a dictionary or another person, together with interlingual and intralingual inferences, is more bottom-up strategies, guessing a meaning on the basis of extra-lingual or contextual cues is more top-down. Explicit vocabulary learning strategies can also be linked with what Oxford (1999) classifies as 'direct strategies' which is learning the target language directly, including cognitive strategies, memory strategies, and compensation (guessing and inferring) strategies. As a result, it can be stated that the elaboration of the newly acquainted word can promote its retention (Anderson, 1985). In Fraser (1999)'s study, it has been shown that inferencing was preferred to be the primary strategy used by the participants (44\%) and they were seen to be generally successful in the post-tests. It is also indicated that the participants were more successful in their retention rates when both inferencing and consulting strategies were applied. This can suggest that a combination of strategies from both implicit and explicit processing can result to be efficiently. Similarly, in Paribahkt and Wesche's (1999) study, the results indicated that the most important strategy adopted by the participants was 'inferencing' (almost $80 \%$ of strategy use), and they also suggest that each participant generally used the same types of strategies in all conditions, which suggests that, when dealing with lexical problems for comprehension, learners apply the same means for solution. Apart from this, they state in their study that participants used several knowledge sources together while inferring a meaning. On the other hand, the research done by Ender (2014) suggests that even though the results indicate that there is significant evidence for the potential of unintentional learning of vocabulary, it has been notified that the participants adopted inferencing only to a minor degree (10\%). She also 
stated in her study that strategy use affected retention significantly and also that different strategies have importantly different effects on learning. According to her results, unknown words that had not been explicitly treated by a processing strategy can be recalled in 11 per cent of the cases, meanings determined by using a dictionary are recalled in 27 per cent of the cases, whereas the retention rate for inference is 57 per cent and that for recall after a combination of the two processes is only 47 per cent. Consequently, the cognitive processing strategies (implicit and explicit) applied while confronted with an unknown vocabulary can give insight to how and to what rate the acquisition was achieved.

\subsection{Research Questions}

This study focuses on the lexical processing strategies adopted by the participants in the study while doing reading-for-comprehension activities together with the effect of these strategies on the retention of the new vocabulary items. As a result, the following two research questions are aimed to be investigated;

1. How do the effectiveness of implicit and explicit processing strategies differ when considering the retention or learning of incidental vocabulary acquisition?

2. How do different implicit processing strategies differ in terms of their effectiveness in incidental vocabulary acquisition?

\section{Method}

\subsection{Research Design}

This experimental study focuses on the effectiveness of implicit and explicit cognitive strategy in incidental vocabulary acquisition. In experiments which investigate incidental vocabulary acquisition, the participants are generally required to perform a task involving the process of some information without being told in advance that they will be tested in terms of identifying their retention of the target word (Laufer and Hulstijn, 2001). A similar methodology was adopted in this study in which the participants were exposed to reading comprehension tasks without being aware of the focus of the study which aims to measure their retention rate of the unknown words they came across during the reading process. Hence the participants were not aware that the focus was on their incidental vocabulary acquisition and they were not aware that a post-test (Vocabulary Knowledge Scale) would be required after the reading comprehension tasks.

\subsection{Participants}

The number of participants who took part in this study is 12 and they were all students from Osmaniye Korkut Ata University-School of Foreign Languages. The participants were taking English courses at the preparatory program. It should also be stated that the preparatory program is based on voluntariness in which the students, who are newly accepted to the university, fill out a form at the beginning of 
the year in which they state whether or not they would like to take English courses before moving on to their courses at their own departments. There were four different courses in total. This study was conducted in the 'Reading and Writing' course. The enrolment of the students to their classes was based on the placement test results which were conducted at the beginning of the year. As a result, since the study was only conducted in one specific class, the students who took part in this study were approximately around the same level of English proficiency level. According to the Oxford Placement Test, which was conducted at the beginning of the 2016-2017 fall semester, the class which took part in the study comprised of A1-A2 level students and their age range was in between 18-21.

\subsection{Materials and Procedure}

Three different data collection tools were applied during the research process. These tools were; Reading session sheets, the Reading-for-Comprehension Exercise and the Follow-up Vocabulary Test. Before applying the tests and the exercises, Informed Consent Forms were handed out in order to inform the students and also to get their approval before conducting the study. During the reading session, the participants were asked to read a text and underline or highlight any unknown word. The main aim here was to identify the unknown vocabulary for each participants in order to identify what strategies they used to deal with the meaning of the same unknown words in the following Reading-for-comprehension exercise. The text used in this process was chosen from the supplementary tasks of 'Q-Skills for Success' of Oxford University Press. As a result, it can be stated that the students were familiar with the topic of the text from their Reading and Writing courses. It should also be stated that the proficiency level of the text was suitable for the participants, hence, it didn't create grammar difficulties. The aim for this was to avoid any language difficulties apart from dealing with vocabulary.

After a few days later, the reading-for-comprehension exercise was conducted. During this process, each student was asked individually in the researcher's office to read the whole text, which was the same text that they had read during the reading session, summarize each paragraph in order to enable the participants to use the words in each paragraph and to ensure comprehension and finally answer the comprehension questions about the reading text. During the summarization, the participants were required to read the text in paragraph by paragraph and give a summary at the end of each paragraph. The participants were also asked to verbalize what they were thinking especially when they came across an unknown words. It should be stated that the students also used their mother tongue during the think aloud process in the Reading-for-Comprehension period. This enabled the researcher to grasp the strategy that the participants adopted while encountering an unknown word. Through these feedbacks the researcher had the chance to achieve immediate retrospective protocols while audio-recording the participants, hence, the researcher was able to identify which cognitive processing strategy the participants adopted while encountering an unknown word. The researcher also took notes throughout this 
process. While keeping notes, questions for clarifications were asked in order to prompt the students, such as 'you seem like you have a problem, tell me what you're thinking," or "Why have you put your finger on that word?," or "You look puzzled." (Paribahkt and Wesche, 1999, p.202). Throughout the process the participants were aware of the fact that they could also use their online dictionaries when they thought it was necessary.

Finally, the follow-up vocabulary test was conducted a week after the reading-forcomprehension exercise. The participants were tested on their retention of the new words which they accounted in the previous reading session and exercises. They were asked to complete the Vocabulary Knowledge Scale (VKS) (see Appendix 3) by Wesche and Paribakht (1996), which was personalized for each of the participants in accordance with their own number of unknown words from the text which the participants had expressed in the reading session, in order to express their level of knowledge for each previously unknown word. As a result, this helped to measure the number of lexical items learned during the treatment.

\subsubsection{Analysis}

Four basic lexical processing strategies of Fraser (1999), was taken into consideration in order to identify the strategies adopted by the participants during incidental vocabulary acquisition. These were; ignoring a word, using an electronic dictionary (explicit processing strategy), inferring the word's meaning from context (implicit processing strategy) and also inferring the word's meaning and later using a dictionary to check it (implicit + explicit processing strategy). See Table 1 for displaying information.

Table 1. Categorization of Fraser's (1999) lexical processing strategies in terms of implicit and explicit cognitive processing.

\begin{tabular}{llll}
\hline Cognitive Processing Strategies & & \\
\hline Explicit & Implicit & Explicit and Implicit & none \\
\hline Consulting a dictionary & Inferring the meaning of & Adopting both strategies & Adopting neither \\
or consulting the & word through contextual or & while encountering an & type of \\
researcher. & intralingual and interlingual & unknown word. & \\
& strategies. & \\
\hline
\end{tabular}

The analysis for the think-aloud protocols was done through transcribing the recorded utterances of the participants. The transcripts and the researcher's notes, which were taken during the reading-for-comprehension period, were taken into consideration while analyzing the lexical processing strategy the participants had adopted. The analysis of the Vocabulary Knowledge Scale (VKS) was done through the procedures (see Table 2) suggested by Wesche and Paribakht (1996). 


\begin{tabular}{ll}
\hline Self-Report Categories & Meaning of Scores \\
\hline I & The word is not familiar at all. \\
\end{tabular}

The main aim of the self-reports was to identify the depth or the level of the knowledge of the newly acquired vocabulary. As for the scoring of the self-reports, as can be seen in Table 2, the first category, which indicates that the participant does not know the word at all, has a score of ' 1 '. The second category of the self-reports, which indicates that the word is familiar but the meaning is not, has a score of ' 2 '. In the third category, if the participant manages to write the correct synonym or the translation of the required vocabulary, he/she receives a score of ' 3 ', on the other hand, if the synonym or the translation is incorrect, the participant receives a score of ' 2 '. In the fourth category, if the participant manages to use the word in a sentence semantically appropriate, it was scored as ' 4 ', otherwise, the scoring will be done accordingly in other cases. As for the fifth category, it remains at its original level if the word is used semantically and grammatically correct in a sentence. On the other hand the scoring will be done appropriately as ' 2,3 or 4'. Another factor which was taken into consideration in the VKS scoring categories is to identify the groups in which the participants have shown some type of growth or haven't proceeded at all. In order to achieve this, the first two self-report categories were grouped together as "meaning not recalled" and the third, fourth and fifth self-report categories are grouped as 'meaning recalled'.

\section{Results}

The results of the study indicate that there were 105 instances in which the participants came across unknown vocabulary, ranging from 9 to 11 unknown vocabulary per participant $(\mathrm{M}=8.5, \mathrm{SD}=1.93)$. among these instances, the participants used lexical strategies '95' times and aimed to ignore the unknown words in '10' instances. As can be seen in Figure 1, the most frequently observed lexical strategy adopted in incidental vocabulary acquisition has resulted to be 'consulting' (44\%) which is followed by 'inferring' (25.7\%), 'infer and consulting' (20\%) and 'ignoring' (9.5\%). As a result, it can be inferred that while $44 \%$ of the participants adopted explicit processing strategies, $25.7 \%$ adopted implicit processing strategies and $20 \%$ adopted both types. 


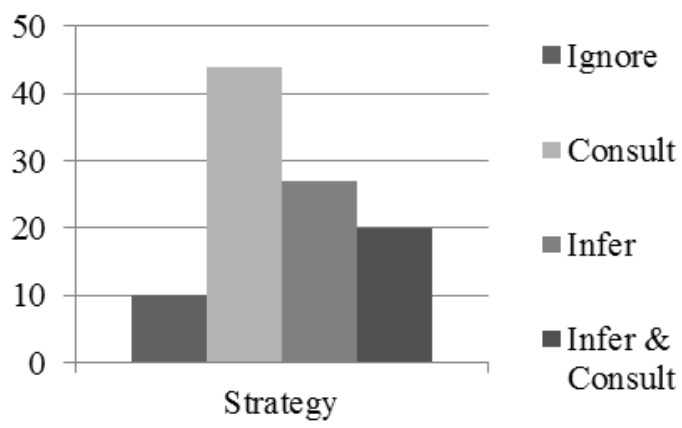

Figure 1. The occurence of the cognitive processing strategies.

As for the implicit processing strategies which has been categorized among three different subgroups (interlingual, intralingual and contextual), the results of the study state that while the most frequently observed strategy is contextually inferring the meaning of an unknown word (37.5\%), this was followed by inferring meaning from interlingual cues (35.42\%) and intralingual cues (27.08\%) (see Figure 2 for visual representation).

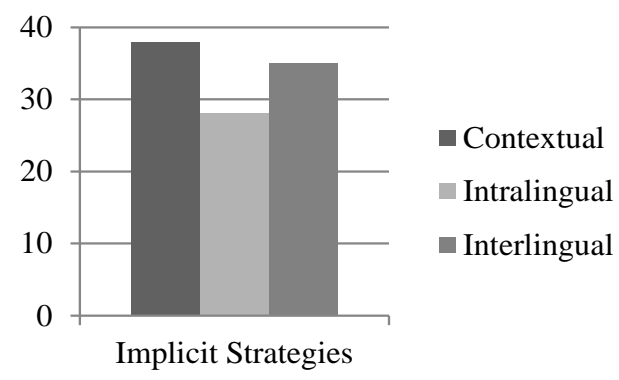

Figure 2. The occurrences of 3 different types of implicit processing strategies.

Apart from the frequencies of occurrences; in terms of effectiveness in L2 vocabulary retention in incidental vocabulary acquisition, which has been induced from the Vocabulary Knowledge scale scores (Min=1, Max=5) (see Table 2), it has been seen that among the four lexical processing strategies, inferring has resulted to be the most effective in terms of learning new vocabulary in incidental circumstances $(M=4$, $\mathrm{SD}=1.02)$. Inferring was followed by 'inferring and consulting' $(\mathrm{M}=3.4, \mathrm{SD}=1.3)$, 'consulting' ( $\mathrm{M}=2.7, \mathrm{SD}=1.32)$ and 'ignoring' $(\mathrm{M}=2.2, \mathrm{SD}=1.32)$ (see Figure 3 for visual representation). 


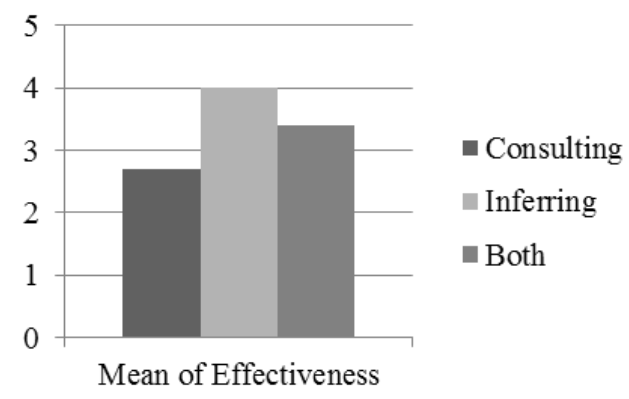

Figure 3. The effectiveness of lexical processing strategies in terms of Vocabulary retention.

The 5-point Vocabulary Knowledge Scale was sub-grouped into two categories as 'meaning recalled and meaning not recalled'. While the first two scores were given to participants who did not recall the target vocabulary item, the remaining scores $(3,4$ and 5) were given to participants who recalled the meaning of the target vocabularies in accordance.

Table 3. The frequency and percentages of the Vocabulary Knowledge Scores in relation to lexical processing strategies and inferencing subgrops.

\begin{tabular}{lllllllll}
\hline & & \multicolumn{2}{l}{ Lexical processing Strategies } & \multicolumn{3}{l}{ Inferencing Subgroups } \\
\cline { 3 - 9 } & & $\begin{array}{l}\text { Ignore } \\
(\mathrm{n}=10)\end{array}$ & $\begin{array}{l}\text { Consult } \\
(\mathrm{n}=47)\end{array}$ & $\begin{array}{l}\text { Infer } \\
(\mathrm{n}=27)\end{array}$ & $\begin{array}{l}\text { Infer \& } \\
\text { Consult } \\
(\mathrm{n}=21)\end{array}$ & $\begin{array}{l}\text { IntraL. } \\
(\mathrm{n}=13)\end{array}$ & $\begin{array}{l}\text { InterL. } \\
(\mathrm{n}=17)\end{array}$ & $\begin{array}{l}\text { Contextual } \\
(\mathrm{n}=18)\end{array}$ \\
\hline $\begin{array}{l}\text { Meaning } \\
\text { not }\end{array}$ & Score1 & $3(30 \%)$ & $8(17 \%)$ & 0 & $1(5 \%)$ & 0 & $1(6 \%)$ & 0 \\
recalled & Score2 & $5(50 \%)$ & $19(41 \%)$ & $2(7 \%)$ & $6(29 \%)$ & $2(15 \%)$ & 0 & $6(33 \%)$ \\
$\begin{array}{l}\text { Meaning } \\
\text { recalled }\end{array}$ & Score3 & 0 & $5(11 \%)$ & $8(30 \%)$ & $3(14 \%)$ & $4(32 \%)$ & $6(35 \%)$ & $1(6 \%)$ \\
& Score4 & $1(10 \%)$ & $9(19 \%)$ & $6(22 \%)$ & $6(29 \%)$ & $5(38 \%)$ & $4(24 \%)$ & $3(17 \%)$ \\
& Score5 & $1(10 \%)$ & $6(12 \%)$ & $11(41 \%)$ & $5(23 \%)$ & $2(15 \%)$ & $6(35 \%)$ & $8(44 \%)$ \\
\hline
\end{tabular}

As can be seen in Table $3,80 \%$ of the participants who ignored the target vocabulary did not recall the meaning in the Vocabulary Knowledge Scale (VKS), but surprisingly $20 \%$ of the participants recalled the meaning of the ignored target vocabulary. Consulting the researcher or a dictionary on the other hand was observed the most frequent. Among these observations, $58 \%$ of the participants who consulted unknown lexical items did not recall them in the VKS, while the remaining $42 \%$ was able to recall the meaning of the words they consulted during the reading-forcomprehension exercise period. $7 \%$ of the participants who inferred the meaning of the target vocabulary through contextual cues or intralingual and interlingual components, did not recall the meaning of the lexical items, whereas a majority of $93 \%$ did recall the meaning of the unknown words in the VKS. Among the subgroups of inferring, it has been observed that $15 \%$ of the participants who used intralingual cues did not recall the meaning of the target words, whereas $85 \%$ of the participants who adopted this strategy resulted to recall the meaning of the target word in the VKS. As for interlingual inferrencing, while $6 \%$ of the participants did not recall the meaning of the words, the remaining $94 \%$ recalled the meanings. on the other hand, 
$33 \%$ of the final subgroup of inferring, which is inferring from contextual cues, resulted with not recalling the meaning of the target vocabulary, while $67 \%$ recalled the meaning of the lexical items in the VKS. Going back to the lexical processing strategies, the final strategy which is a combination of both consulting and inferring resulted to be effective in terms of retention (93\%).

\section{Discussion and Conclusion}

In the present study, among the lexical processing strategies defined by Fraser (1999), which are ignoring, consulting, inferring and both inferring and consulting, it has been found that 'consulting' strategy has been adopted the most during the 105 instances in which the participants used a lexical processing strategy. This result is similar to Ender's study (2014) in which consulting a dictionary was seen to have occurred the most frequently. This suggests that the majority of the participants employed an explicit attempt to figure out the meaning of a word in incidental vocabulary acquisition circumstances. These results differ in similar studies, for instance in Paribakht and Wesche's (1999) study the most frequently observed strategy had been inferring (80\%), similar to Fraser's (1999) study in which inferring was observed to be adopted $58 \%$ of the total instances. The varying results may be due to the context of the study. Taking into consideration the level of the participants (elementary) together with their learner background, which consists of multiplechoice-question based learning, memorization and also in which possessing information is rather easy due to social media and the internet, it is not a surprise to see that the participants adopted 'consulting a dictionary or researcher' in order to gain the required information. But it has still been notified that despite 'consulting' being the most frequently adopted strategy, 'inferring' has been observed to be the following most frequently adopted strategy in the present study. Another surprise in the study which was different from similar studies was the frequency level of 'ignoring'. In the present study it has been seen that participants ignored the unknown words 9.5\% of the total instances, whereas Paribakht and Wesche (1999) state that the participants ignored half the unknown words and Fraser (1999) also state that his participants adopted 'ignoring' in $32 \%$ of the total instances. This may be due to the fact that in the present study the researcher put emphasize on the unknown words during the reading-for-comprehension period by asking questions whose answers contained information requiring the meaning of the unknown words. It has been notified that inferring the meaning of an unknown word resulted to be more effective in terms of retention based on the Vocabulary Knowledge Scale. An Example from the audio-records from the Reading-for-Comprehension treatment can be seen in Extract 1.

Extract 1: "While they are sleeping their bodies..digest..sindirim galiba, çünkü uyurken yiyecekleri sindiririz." (I think it means 'digest' because we digest our food when we sleep) 
The effectiveness of the lexical processing strategies is similar in relevant studies. For instance, Fraser (1999) states that generating word meaning from linguistic or situational elements through sense creation results better in the retention of vocabulary since a context-centered, more deliberate and effortful process takes place, he also states in his study that $78 \%$ of the inferring attempts resulted to be effective in terms of retention in the posttest. This can also be related to Hulstijn's (1992) study in which it is stated that information which has been gained with more mental effort can later be better retrieved and recalled much easier than information that has been attained with less mental effort. He also stated in his study that, when the participants were required to infer the meaning of a word through the context, the retention of these words were better than the retention of those words in which the participants were only given synonyms to learn their meanings. Paribakht and Wesche (1999) also state that inferring the meaning of a word was regarded to be the most important strategy in identifying word meaning. Similarly, in Williams' (2005) study, it is stated that implicit processing can lead to successful learning and retention. As a result, it can be stated that processing new lexical information more elaborately by paying attention to its pronunciation, orthography, grammatical category, meaning and semantic relations to other words, can lead to better retention than processing new lexical items which don't cover similar involvements (Laufer and Hulstijn, 2001)

As for the implicit processing strategies, it has been seen that 'contextual inferring' had been adopted the most (37.5\%), which was followed by 'interlingual inferring' (35.4\%). The example can be seen in Extract 2 for contextual inferring and Extract 3 for interlingual inferring.

Extract 2: "Immunization is important..but I don't know immunization..but 'hastalıklara karşı bağşılklık kazanılabilir, bağışılklı olabilir.”' (but we immunize against illnesses, it may mean 'immunization'.)

Extract 3: "Impossible..korumak, çocuklarını korumak..infection..enfeksiyon galiba, enfeksiyondan, hastallklardan korumak." (impossible.. to protect, protect the children..'infection'..I think it means 'enfeksiyon', protect the children from infection and diseases.)

In Ender's (2014) study, it was found that inferring through extralingual and contextual cues was observed to be the most frequent, but differing from the present study it had been reported that inferring through intralingual cues was observed to be greater than interlingual cues. As for the effectiveness of the subgroups of these implicit cognitive strategies, Ender's (2014) study found that inferring through linguistic associations resulted better in retention in contrast to inferring through contextual cues. So, in other words bottom-up strategies in this instance resulted better than top-down strategies, since as Qian (2004) states while interlingual and intralingual are more bottom-up strategies, guessing meaning on the basis of extra lingual or contextual cues are more top-down. As for the effectiveness of the subgroups of the implicit processing strategies in the present study, it has been observed 
that interlingual inferring resulted more effectively in terms of retention, which was followed by contextual inferring. However, certain instances, in which intralingual inferring occurred, did not result effectively in terms of retention in the vocabulary Knowledge scale. This is intriguing since as mentioned before, in similar research it was found that intralingual inferring resulted effectively in the posttest. The reason for this may be due to the level of L2 of the participants. It may be assumed that they still lack the ability to deduce forms and meanings from the target language since they are not acquainted enough. The example can be seen in Extract 4 in which a participant infers a meaning through intralingual guesses.

Extract 4: “..build up the hormones..hormonlar inşa..yani geliştiriyor, oluşturuyor değil mi??" (build up the hormones.. they 'build' the hormones, I mean they develop, they form right?)

As a result, it can be assumed from the present study that similar to what Paribahkt and Wesche (1999) state both in first and second language development most vocabulary learning can occur naturally when learners try to understand the meaning of the new words they hear or read in context. The findings of this study also support this idea since in 58\% of the instances; the participants were noticed to have achieved to recall the meaning of the intended vocabulary. Furthermore, among these instances the attempt to infer the meaning of the word has resulted to a better retention in the VKS, suggesting that implicit cognitive processing strategies can be more beneficial in terms of incidental vocabulary acquisition in the present study. This can be linked to what Ellis (2005) states as the accessibility of knowledge in which it is stated that implicit processing of newly acquired knowledge can lead to being deeply embedded knowledge which allows for automatic processing. Apart from this it has also been noticed that, while investigating the subgroups of implicit processing strategies, applying interlingual inferring strategy has resulted to be of greater benefit in regard to inferring from context or intralingual cues. This can be linked to Fraser's (1999) statement: "Inferencing through word identification is characterized as a fast, automatic, data-driven process in which the form of the unfamiliar word activates an L1 or L2 association in the learner's mental lexicon." (p. 231). The surprising fact, however, was how intralingual inferencing didn't result to be as effective as the other subgroups. This fact can be a recommendation for further studies in related research areas.

\section{References}

Anderson, J. R. (1985). Cognitive psychology and its implications. A series of books in psychology.

Ellis, N. C. (1994). Implicit and explicit language learning. Implicit and explicit learning of languages, 79-114.

Ellis, R. (2005). Measuring implicit and explicit knowledge of a second language: A psychometric study. Studies in Second Language Acquisition, 27(2), 141-172.

Ender, A. (2014). Implicit and explicit cognitive processes in incidental vocabulary acquisition. Applied Linguistics, 37(4), 536-560. 
Fraser, C. A. (1999). Lexical processing strategy use and vocabulary learning through reading. Studies in Second Language Acquisition, 21(2), 225-241.

Gass, S. (1999). Incidental Vocabulary Learning. Studies in Second Language Acquisition, 21(2), 225-41

Hulstijn, J. H. (1992). Retention of inferred and given word meanings: Experiments in incidental vocabulary learning. In J. L. A. Pierre, \& H. Béjoint (Eds.), Vocabulary and applied linguistics (pp. 113-125). London, UK: Macmillan.

Hulstijn, J. H. (2005). Theoretical and empirical issues in the study of implicit and explicit second-language learning: Introduction. Studies in Second Language Acquisition, 27(2), 129-140.

Hulstijn, J. H. (2008). Incidental and intentional learning. The Handbook of Second Language Acquisition, 349-381.

Joe, A. (1998). What effects do text-based tasks promoting generation have on incidental vocabulary acquisition?. Applied Linguistics, 19(3), 357-377.

Krashen, S. (1989). We acquire vocabulary and spelling by reading: Additional evidence for the input hypothesis. The Modern Language Journal, 73(4), 440-464.

Laufer, B. (1990). Ease and difficulty in vocabulary learning: Some teaching implications. Foreign Language Annals, 23(2), 147-155.

Laufer, B., \& Hulstijn, J. (2001). Incidental vocabulary acquisition in a second language: The construct of task-induced involvement. Applied linguistics, 22(1), 1-26.

Paribakht, T. S., \& Wesche, M. (1997). Vocabulary enhancement activities and reading for meaning in second language vocabulary acquisition. Second Language Vocabulary Acquisition: A Rationale for Pedagogy, 55(4), 174-200.

Paribakht, T. S., \& Wesche, M. (1999). Reading and "incidental" L2 vocabulary acquisition. Studies in Second Language Acquisition, 21(2), 195-224.

Williams, J. N. (2005). Learning without awareness. Studies in Second Language Acquisition, 27(2), 269-304.

\section{Copyrights}

Copyright for this article is retained by the author(s), with first publication rights granted to the Journal.

This is an open-access article distributed under the terms and conditions of the Creative Commons Attribution license (CC BY-NC-ND) (http://creativecommons.org/licenses/by-nc-nd/4.0/). 